\title{
БЕЗОПАСНОСТЬ ХИРУРГИЧЕСКОЙ ПОМОЩИ: ЭЛЕМЕНТЫ СИСТЕМНОГО ПОДХОДА К ПРОБЛЕМЕ. ЧАСТЬ 1
}

\section{SURGICAL CARE OF SAFETY: ELEMENTS OF A SYSTEM APPROACH TO THE PROBLEM. PART 1}

\author{
A. Karsanov \\ A. Kultciev \\ S. Maskin \\ A. Korovin \\ T. Derbentseva \\ O. Remizov
}

Summary. Modern medicine is completely unsafe for patients and representatives of medical personnel. To a large extent, this is facilitated by the fact that almost everywhere in medical organizations there is no wide practice for accurate registration, analysis of the causes of unwanted medical events and timely adjustments to the further treatment process. The most important condition that can increase the efficiency of medical activities is the implementation of a systematic approach to improving patient safety. The review presents the main elements of a systemic solution to this problem in modern surgery, such as standardization, risk management and personnel management.

Keywords: surgery, patient safety, systems approach, standardization, risk management, personnel management.
Карсанов Алан Мухарбекович

К.м.н., доцент, ФГБОУ ВО «Северо-Осетинская государственная медицинская академия»

(2. Владикавказ)

karsan@inbox.ru

Кульчиев Ахсарбек Агубеевич

Д.м.н., профессор, ФГБОУ ВО «Северо-Осетинская государственная медицинская академия»

(2. Владикавказ)

kulchiev.ahsarbek@yandex.ru

Маскин Сергей Сергеевич

Д.м.н., професссор, ФГБОУ ВО «Волгоградский государственный медицинский университет»

(г. Волгоград)

maskins@bk.ru

Коровин Александр Яковлевич

Д.м.н., профессор, ФГБОУВО «Кубанский государственный медицинский университет»

(2. Краснодар)

kuman52@mail.ru

Дербенцева Татьяна Викторовна К.м.н., дочент, ФГБОУВО «Волгоградский государственный медицинский университет»

(2. Волгоград)

TVDerbentseva@volgmed.ru

Ремизов Олег Валерьевич

Д.м.н., ректор ФГБОУ ВО «Северо-Осетинская государственная медицинская академия»

(2. Владикавказ)

oleg_remizov@mail.ru

Аннотация. Современная медицина до конца небезопасна для пациентов и представителей медицинского персонала. В немалой степени этому способствует то, что практически повсеместно в медицинских организациях отсутствует широкая практика по четкой регистрации, анализу причин нежелательных медицинских событий и внесению своевременных корректив в дальнейший лечебный процесс. Важнейшим условием, способным повысить эффективность медицинской деятельности является реализация системного подхода к повышению безопасности пациентов. В обзоре представлены основные элементы системного решения указанной проблемы в современной хирургии, такие как стандартизация, рискменеджмент и управление персоналом.

Ключевые слова: хирургия, безопасность пациентов, системный подход, стандартизация, риск-менеджмент, управление персоналом. 


\section{Ввемение}

$\mathbf{H}$ есмотря на широкое развитие информационных и специальных медицинских технологий, нельзя признать, что современная медицина до конца безопасна для пациента и для представителей медицинского персонала. Более 10 лет назад ВОЗ признала, что даже в развитых странах здоровью каждого десятого пациента причиняется вред во время его лечения в больнице [1].

Большинство из нежелательных медицинских событий клинически незначительны и не имеют серьезных последствий для исхода лечения [2]. Тем не менее, после изучения нежелательных последствий лечения в США было установлено, что от 44 до 98 тыс. пациентов стационаров погибли от так называемых "медицинских ошибок" [3, 4].

Настораживает, что даже в наше время практика по четкой регистрации, по поиску причин их возникновения и, главное,- по внесению разумных корректив в дальнейший лечебный процесс после выяснения причин произошедшего, пока не стала систематической повсеместно, в рамках общенациональных систем здравоохранения [5].

Можно быть уверенным, что вопрос профилактики и нивелирования последствий нежелательных событий в медицине выйдет на одно из первых мест по значимости. Ведь возрастающая финансовая нагрузка на систему здравоохранения страны или конкретной медицинской организации требует коренной перестройки организации лечебного процесса, основанной на культуре безопасности медицинской деятельности [6, 7].

Все сказанное выше относится в первую очередь к высокорисковым областям медицинской деятельности, а хирургия является одной из них $[4,8,9]$. Если ранее, исторически проблемы безопасности в клинике были вызваны недостатком наших знаний о ключевых факторах риска осложнений и несовершенством лечебных технологий, то в результате научно-технического прогресса подобные системные недостатки хирургами успешно преодолевались $[8,10]$.

Ниже будут рассмотрены основные элементы системного принципа управления качеством и безопасностью хирургической помощи (БХП).

\section{СтанАартизация}

Большинство из современных организационных подходов, направленных на повышение БХП, сводится к трем взаимодополняющим направлениям [11]:
- к созданию эффективной системы выявления и идентификации нежелательных клинических событий;

- к созданию конструктивного механизма по анализу и недопущению потенциальных рисков нежелательных событий;

- к разработке эффективных неотложных мер по нивелированию последствий негативных событий в процессе лечения каждого пациента.

В основу триединства ключевых направлений повышения БХП положен принцип стандартизации [11]. Стандартизация системы управления (менеджмента) качеством и безопасностью медицинской деятельности является сегодня прогрессивной моделью администрирования в медицине.

Согласно ГОСТ Р1.0-92, стандартизация - это деятельность, направленная на достижение оптимальной степени упорядочения в определенной области, посредством установления положений для всеобщего и многократного использования в отношении реально существующих и потенциальных задач. Стандартизовано должно быть все то, что может быть измерено, зарегистрировано, подвергнуто анализу и усовершенствованно. Позитивным примером подобного подхода является использование хирургических чек-листов [12].

Причем важна не сама по себе стандартизация как унифицированный принцип организации маршрутизации когорт пациентов со схожей патологией или как принцип формирования групп однородных нозологий и тактики их диагностического (лечебного) сопровождения. Главным содержанием принципа стандартизации в медицине является соблюдение равнозначно высокого уровня понимания клинической сущности той или иной нозологии и технологий ее оздоровления всеми представителями хирургического сообщества, вне зависимости от государственных границ и экономического состояния отдельных стран, а тем более в рамках хирургической службы одного медицинского учреждения [10].

В контексте обсуждаемых прикладных вопросов качества и БХП этот краеугольный принцип означает стандартное и безусловное обеспечение высокого уровня качества и безопасности хирургического лечения, вне зависимости от любых, а их обычно при лечении хирургического пациента бывает несколько, привходящих обстоятельств [4].

В соответствии с Федеральным законом № 323Ф3, допустимыми для совершенствования ориентирами для стандартизации структуры, процесса и технологий оценки результата лечебной деятельности должны быть: порядки, клинические рекомендации (являющи- 
еся результатом предложений профессиональных общественных объединений специалистов) и стандарты оказания медицинской помощи (которые разрабатываются Минздравом РФ), именно в такой логической последовательности $[6-8,10,11]$.

В формальном понимании для роста БХП хирургическая служба должна соответствовать целому ряду высоких стандартов [6, 7, 10]. Она должна быть стандартно укомплектована квалифицированными и высокомотивированными кадрами, современными изделиями медицинского назначения и технологиями оказания хирургической помощи $[7,11]$. В ней стандартно должны соблюдаться и соответствующим образом оформляться права пациентов и медицинских работников. Должен быть внедрен высокий стандарт оценки и мониторинга качества и безопасности медицинской деятельности $[6,7,10,13]$.

Системный принцип стандартизации в медицинской отрасли должен распространяться на управленческие, инфраструктурные, клинические, образовательные, информационные и другие компоненты эффективного функционирования современной медицинской организации $[10,11,13]$.

Одним из важных современных факторов повышения БХП является стандартизация в рамках доказательных принципов своевременной диагностики, эффективного лечения и ранней реабилитации пациентов $[8,10]$. Не достаточно просто стандартизовать тактику диагностического сопровождения хирургических пациентов и разработать шаблоны выполнения процедур и оперативных вмешательств (по аналогии с повсеместно внедряемыми стандартными операционными процедурами) [14].

Ключевым принципом, предостерегающим медицинскую организацию от того, чтобы не превратить стандартизацию в стагнацию является понимание сущности процессного подхода к решению абсолютно всех основных и вспомогательных процессов, составляющих комплекс хирургической деятельности $[10,11]$. Цикличность и научная наполненность последовательно производимых действий: планирования, реализации, анализа эффективности и усовершенствования, является лаконичной, понимаемой всеми и запрограммированной на перманентное развитие формой существования высоких стандартов хирургической службы. С каждым новым циклом усовершенствования утверждается более высокий уровень стандарта качества и БХП [10, 14].

\section{Риск-менеАжмент}

В современной клинике должны быть внедрены современные методы идентификации личности и профи- лактики падений пациентов. При трансфере пациентов между отделениями и при сменном характере работы персонала одного структурного подразделения необходимо соблюдать формализованные требования к процессу передачи клинической ответственности за пациента [7].

Говоря об основном, оперативном компоненте хирургического лечения, следует знать принципы профилактики рисков наиболее часто встречающихся осложнений у конкретной категории хирургических больных [10]. Так, как минимум, персонал хирургического отделения должен согласованно обеспечить:

- профилактику хирургических вмешательств ошибочной локализации;

- профилактику неконтролируемых геморрагий;

- профилактику любого вида инфекций, связанных с оказанием медицинской помощи;

- профилактику венозных тромбоэмболических осложнений;

- профилактику получения электо-, термо-, баротравмы пациентом во время применения изделий медицинского назначения;

- не допустить возгораний в операционных помещениях и общего переохлаждения пациента;

- профилактику пролежней в послеоперационном периоде [10, 11, 12, 15].

Что еще может угрожать здоровью хирургического пациента? Мы не должны забывать, что хирургический пациент получает не только оперативное лечение, но разного объема медикаментозную терапию. Побочное действие лекарств и их сочетаний является задекларированной производителем данностью. Вот почему стандартизация принципов лекарственной безопасности и поиск эффективных технологий управления рисками сопроводительного по отношению к основному оперативному методу лечения каждого пациента - это важнейшие элементы организации хирургического лечения. Безусловно, никто не оправдает сотрудников хирургической службы, которые не соблюдают принципы лекарственной безопасности пациентов, поскольку эта категория нежелательных клинических событий всегда актуальна для абсолютно любой медицинской деятельности $[6,7]$.

Только из простого перечисления основных рисков и набора симметричных им превентивных действий, становится понятно, что заниматься в каждом лечебном случае суммированием разнохарактерных мероприятий по нивелированию патогенеза нежелательных событий и пытаться синхронно совместить различные по направленности усилия персонала смежных хирургических служб, не всегда продуктивно на практике [4, $10]$. 
Слишком широкий диапазон действий необходимо производить с учетом важности соблюдения двух взаимопротиворечащих подходов: стандартизации обследования и предоперационной подготовки и персонализированного подхода к профилактике и лечению разнообразных осложнений $[8,12]$. И в этом нам видится один из стержневых факторов неудач мероприятий по недопущению нежелательных медицинских событий в реальной практике. Риск-менеджмент или предупреждающая оценка риска опасной для пациента ситуации - это то, что в широком смысле должно быть положено в основу системного подхода к БХП $[10,16]$.

На сегодня повсеместно распространяются принципы научной организации хирургического процесса, базирующиеся на результатах исследований в рамках медицины, основанной на доказательствах $[8,16]$. Причем в медицине давно уже стерты все условные границы между концептуальными подходами к достижению высокого качества и безопасности хирургической деятельности в системах здравоохранения разных стран [1, 5, 8, $10,11]$. Знания и медицинская наука развивается по единым для глобального пространства законам. Отличия между странами и, соответственно, между различными национальными моделями развития хирургии, состоит лишь в разном уровне материального и технического обеспечения реальной клинической практики.

\section{Управ^ение персона^ом}

При самой совершенной технологии лечебного процесса и высоком техническом обеспечении медицинской отрасли следует помнить, что влияние человеческого фактора и скрытых системных недостатков на конечный результат лечебной деятельности порой невозможно предугадать [1, 3-5]. Осознавать, что гдето есть примеры высокого и может быть даже наиболее высокого стандарта качества хирургической помощи, этого не достаточно для того, чтобы прогрессивные технологии были успешно внедрены в любой медицинской организации $[3,9,10,16]$. Как минимум, для этого необходимо спланировать и в короткие сроки реализовать перспективно-ориентированную кадровую политику, логически запрограммированную на перманентное саморазвитие в рамках системы высоких стандартов качества и БХП, а это далеко не повсеместно возможно сделать $[5,10,11]$.

Чтобы работа по основным корректирующим направлениям повышения БХП была стандартизована, от сотрудников хирургической службы современной медицинской организации требуется осознавать свою персональную ответственность в рамках ежедневных должностных обязанностей. Сегодня уже невозможно говорить о безопасности в таком хирургическом отде- лении, где сотрудники не понимают необходимость совершенствования применяемых форм коммуникации и взаимодействия как между персоналом, так и с пациентами [7].

Эффективное управление деятельностью медицинского персонала является обязательным компонентом системных реформ в обеспечении высоких стандартов качества и безопасности хирургической помощи $[5,7$, 10]. В реальности же не редки ситуации, когда новому руководителю приходится разрабатывать и реализовывать план развития хирургической службы с тем персоналом, который привык к прежним условиям работы, результат которой и привел к необходимости системных реформ [6, 7]. Вот почему освоение принципов эффективного управления медицинским персоналом является самым трудоемким, болезненным, длительным по продолжительности освоения первичных, базовых навыков прогрессивных "горизонтальных" производственных связей с представителями смежных служб и высокорискованным "предприятием" в части ожидания долгосрочных положительных результатов.

Искаженное личностное или коллективное мышление ретроградно ориентированного медицинского персонала можно сравнить с "бомбой замедленного действия". Здесь подходит меткое выражение “...маленькая некомпетентность или незначительная оплошность одного сотрудника - это большая проблема для всей медицинской организации и смертельная опасность для каждого пациента".

В слаженных, обученных коллективах роль каждого отдельного медицинского работника незаметна, до той поры, пока не случится личностный, человеческий "сбой" и сотрудник совершит непреднамеренное нежелательное действие. Мы можем наблюдать последствия таких личностных сбоев в самых разных сферах жизнедеятельности человека, однако наиболее тяжелые последствия таких ошибок для популяции бывают в сфере автотранспорта, гражданской авиации, атомной промышленности, в военной отрасли [5].

Однако в медицине тяжесть последствий для каждого пациента может быть столь же драматичной и не преодолимой, сколь она выглядит ничтожно малой, если судить по нашей национальной статистике учета подобных событий. И хотя в указанных выше областях деятельности человека давно разработаны технологии безопасности и недопущения ошибок, подобные явления не исключены именно ввиду человеческого фактора. Вот почему мы уверены, что качество и безопасность в современной хирургии нельзя обеспечить без постоянного совершенствования технологий управления хирургическим персоналом. 


\section{Зак^ючение}

Хирурги постоянно пытаются совершенствовать свое профессиональное мастерство. Совместно с представителями медицинской индустрии они разрабатывают и внедряют передовые, а значит наиболее безопасные для пациента, технологии оказания помощи при самых сложных клинических ситуациях и у самых отягощенных коморбиностью категорий больных. Важнейшим этапом на этом пути становится признание факта нефатальности и предотвратимости нежелательных последствий хирургического лечения. Так, к примеру, в нашей стране было с проектом "Территория безопасности от венозных тромобоэмболических осложнений".

При широком взгляде на лечебную деятельность в рамках международных систем стандартизации клинических разделов медицинской отрасли становится очевидным, что хирургия является одной из важнейших сфер профессиональной деятельности, требующих непрерывного повышения безопасности пациентов.

Важность системного восприятия и решения проблем повышения безопасности лечения вытекает из стандартизации четырех направлений последовательных действий хирургического коллектива, базирующихся на процессном подходе:

- предупреждающей оценки риска опасной ситуации,

- своевременного выявления нежелательного клинического события,

- нивелирования его последствий,

- тщательного анализа причин осложнения и внесения срочных, а главное - конструктивных кор- ректив в технологический процесс, что должно восприниматься и внедряться в медицинской организации как новый, более высокий стандарт БХП. В этом суть проактивного подхода к любой проблеме, в отличие от реактивного, ретроградного по сути и распространенного в большинстве медицинских организаций страны, в рамках прежних регламентирующих документов.

Может возникнуть вполне резонный вопрос, а кто и в рамках каких должностных обязанностей должен руководить системным подходом к обеспечению безопасности хирургического лечения в конкретной медицинской организации? Конечно - это руководитель хирургической службы медицинской организации. Но есть ли у него нужные компетенции?

Для нашей страны ответ достаточно простой и здесь мы поддерживаем усилия государственных органов управления здравоохранением в том, что руководители медицинских подразделений и служб, помимо подготовки по своей клинической специальности, должны получить образование по специальности "общественное здоровье и организация здравоохранения". Их подготовка должна быть акцентированной в первую очередь на современных технологиях управления в здравоохранении в форме непрерывного медицинского образования.

Таким образом, главный вывод из анализа основных элементов системного подхода к повышению качества хирургической деятельности состоит в том, что улучшение уровня организации клиники и постоянное совершенствование медицинского персонала являются залогом непрерывного роста безопасности пациентов.

\section{ЛИТЕРАТУРА}

1. Безопасность пациента / пер. с англ. под ред. Е.Л. Никонова. М.: ГЭОТАР-Медиа, 2010. 174 с.

2. Дедов И.И., Мельниченко Г.А., Трошина Е.А. и др. Объемные образования надпочечников (диагностика и дифференциальная диагностика). Методические рекомендации для врачей, оказывающих специализированную медицинскую помощь (сокращенный вариант) // Consilium medicum.2009. - № 12.- C. 76-94.

3. Medical errors in the USA: human or systemic? // The Lancet.— № 2011. — № 377(9774). — P. 1289.

4. Stahel P.F., Mauffrey C., Butler N. Current challenges and future perspectives for patient safety in surgery // Patient Saf. Surg. — 2014. — № 8. — P. 9. D0I: org/10.1186/1754-9493-8-9

5. Повышение качества медицинской помощи и безопасности пациентов в медицинских организациях: наглядное руководство / Под. ред. Панисар С.С. и др. М.: ГЭОТАР-Медиа, 2016. 160 с.

6. Мурашко М.А. Качество медицинской помощи: пора меняться // Вестник Росздравнадзора. — 2017. — № 1. — С. 10-21.

7. Мурашко М.А., Иванов И.В., Князюк Н.Ф. Основы обеспечения качества и безопасности медицинской деятельности. М.: Вива-Стар, 2020. 406 с.

8. Кубышкин В.А. Безопасная хирургия и клинические рекомендации // Хирургия. - 2014. — № 5. - С. 4-6.

9. Мяконький Р.В., Иванченко С.В. Опорные симптомы острого аппендицита // Альманах Института хирургии им.А.В. Вишневского.— 2017.— № 2.—C. 129.

10. Карсанов А.М. Система менеджмента качества и безопасность пациента в хирургии // Вестник Росздравнадзора.— 2017.— № 6. — С. 52-56.

11. Ройтберг Г.Е., Кондратова Н.В. Медицинская организация по международным стандартам качества: практическое руководство по внедрению. М.: МЕДпресс-информ, 2018. 150 с. 
12. Тимербулатов В.М., Тимербулатов Ш.В. Обеспечение безопасности в хирургии // Вестник хирургии. — 2017.— № 2.—C. 83-85.

13. Полянцев А.А., Мяконький Р.В. Историческая связь русской и немецкой хирургии // Вестник Гиппократа. — 2006. — № 1.—C. 79

14. Линденбратен А.Л., Сидоренко Н.В., Гололобова Т.В., Шестопалова Т.Н. Роль стандартов операционных процедур в управлении качеством медицинской деятельности // Вестник Росздравнадзора. - 2018. - № 6. - С. 40-44.

15. Карпов 0.Э., Ветшев П.С., Даминов В.Д. и др. Цифровые технологии в клинической хирургии и реабилитации // Хирургия.— 2017.— № 1.— С. 4-14.

16. Быков А.В., Мяконький Р.В., Петров А.В., Панкратов А.И. Аппендэктомия как предиктор профессионализации начинающего хирурга в условиях экстренной хирургии // Альманах Института хирургии им.А.В. Вишневского. - 2017.— № 3. - С. 132.

( Карсанов Алан Мухарбекович ( karsan@inbox.ru ), Кульчиев Ахсарбек Агубеевич ( kulchiev.ahsarbek@yandex.ru ),

Маскин Сергей Сергеевич ( maskins@bk.ru), Коровин Александр яковлевич ( kuman52@mail.ru),

Дербенцева Татьяна Викторовна (TVDerbentseva@volgmed.ru ), Ремизов Олег Валерьевич ( oleg_remizov@mail.ru ).

Журнал «Современная наука: актуальные проблемы теории и практики»

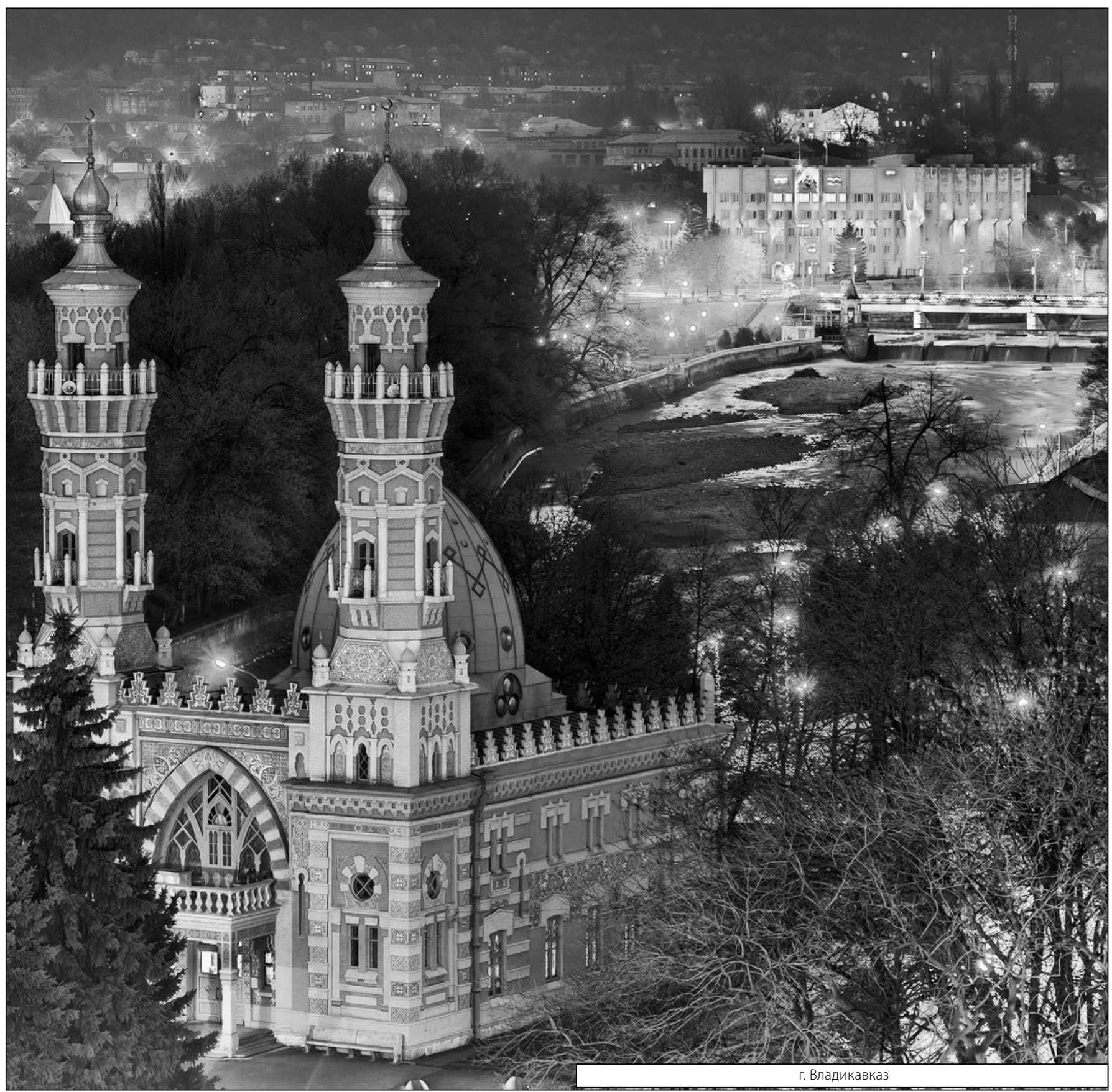

